\title{
XLVI. Description of the coming-up glass telescope
}

\section{Mr. Thomas Jones}

To cite this article: Mr. Thomas Jones (1805) XLVI. Description of the coming-up glass

telescope, Philosophical Magazine Series 1, 22:88, 319-321, DOI: $10.1080 / 14786440508562460$

To link to this article: http://dx.doi.org/10.1080/14786440508562460

曲 Published online: 18 May 2009.

Submit your article to this journal 준

Џ Article views: 5

Q View related articles $₫$ 
and roots, through the bark, has been intercepted: and why some portion of alburnous matter is in all trees * generated below incisions through the bark.

It was my intention this year to have troubled you with some observations on the reproduction of the buds and roots of trees; but as the subject of the paper, which I have now the honour to address to you, appeared to be of more importance; I bave deferred those observations to a future opportunity; and I shall at present only observe, that I conceive myself to be in possession of facts to prove that both buds and roots originate from the alburnous substance of plants, and not, as is, I believe, generally supposed, from the bark.

I am, \&c.

Elton, Dec. 4, 1804:

T. Andrew Knight.

XLVI. Description of the Coming-up Glass Telescope, as made by Mr. Thомas Jones, Mathematical, Optical, and Philosophical Instrument Maker; Pupil of the late Mr. RAMSDEN.

$A_{s}$ it is of much importance, especially in war time, during the chase of a vessel, that the chasing ship should be able to ascertain whether she lessens or increases her distance from the object of which she is in pursuit, $I$ am persuaded the philosophical world will be pleased with a description of an instrument adapted to this useful purpose, invented by the late Mr. Ramsden. It consists in applying a micrometer to a refracting telescope of about two feet long, or to a day and night telescope; and I have been informed by some who were furnished with them by $\mathrm{Mr}$. Ramsden, (and by myself since his death,) that they answer the purpose remarkably well.

To this combination the English sailors have given the name of a coming-up glass. To fit the telescope for this use, the third glass from the eye, in the drawer of the telescope, is divided in two by cutting it across its centre at right angles to its surface; and, in using it, these two semilenses are separated from each other in the direction of their line of separation. By turning a finger-screw on one side

* I have in a former paper stated that the perpendicular shoots of the vine form an exception. I spoke on the authority of numerous experiments; but they had been made late in the summer; and on repeating the same experiments at an earlier period, I found the result ir conformity with my experi. ments on other trees. 
of the eye-tube, each semi-lens forms an image of the same object. These two images will be more or less separated in the proportion of the distance of the centres of the semilenses from each other, which distance is shown in revolutions and parts of a revolution of a finger-screw that separates them. For this purpose a circular head is fixed on the finger-screw, the edge of which is divided into a hundred parts ; and in order to know the number of revolutions, a small slip of brass (that passes over the graduated surface of the head, and serves as its index for showing the centesimal parts of a revolution) is fixed to the eye-tube, and has its chamfered edge also divided, each division being equal to one entire revolution of the screw.

\section{To adjust the Telescope.}

Having, by drawing out the eye-tube more or less, adjusted the telescope to distinct vision, turn the finger-screw till the two images of the same object appear in one, and the edge of the head together with the division numbered 100 will be found at the first division on the index that shows the revolutions.

\section{The use of the Coming-up Glass.}

Having directed the telescope to the vessel chased, turn the finger-screw till the two images of some well defined part of the vessel appear to have their extreme edges in contact with each other; then read off the number of revolutions of the screw shown on the chanfered edge, also the parts of a revolution shown on the edge of the head: then if, after some lime, it be required to know whether we have gained or lost in the chase, again bring the edges of the images of the same object in contact as before. If the number of revolutions and parts of the screw be the same as was shown before, we have neither gained nor lost in the chase. But if the number of revolutions and parts be less, the distance from the chased vessel will be greater in the proportion of the difference of these numbers to the former. On the contrary, if the number of revolutions and parts be greater, we come nearer the vessel in the proportion of the difference of these numbers to the number of revolutions and parts of the first observation.

\section{Example.}

Suppose in the chase of a vessel, by turning the fingerscrew, I bring the image of the main-top-yard to coincide with the main-yard; and, reading off the value, I find it to be three revolutions on the chamfered edge, and 20 parts of 
a revolution on the circular head, which may be wrote 320 ; if, some little time after, by bringing the two images of the same object in contact, I find the number of revolutions and parts to be 360 , the difference of the two observations is 40 , therefore $40: 320:: 1: 8$ (that is, 40, the difference, is to 320 , the first observation, as 1 is to 8 ); consequently, we shall have gained in the chase one-eighth part of the distance: but if at the second observation the number of revolutions be less, for instance 280 , or two revolutions and 80 parts of a revolution; then, as 40 , the difference, is to 320 , the first observation, so is 1 to 8 : consequently we should have lost one-eighth part of our distance in the chase.

No. 120, Mount-street,

Berkeley-square.

XLVII. On the Buds and Ramifications of Plants; the Birth of these Organs, and the organic Relation between the Trunk and the Branches: in a Letter from G. L. Korler, M.D. Professor of Botany and the Materia Medica in the Provisional School of Medicine at Mentz, to $M$. Ventenat, Member of the French National Institute.

[Concluded from p. 241.]

But it may be said, if these observations on the origin of buds are founded in nature, how comes it to pass that herbaceous and so tender bodies should penetrate through a considerable number of ligneous zones, which must be the case in branches of two or three years of age, which, though rarely, produce, however, sometimcs buds? It appears to me very probable, that at the period when the bud becomes expanded, a period which corresponds with the elongation of the medullary sheath, a certain number of the bundles of the tubes of that sheath proceeds laterally from interval to interval towards the bark. Soon after, the first cambium of the bud appears between the nicdullary sheath and the bark, and separates these two parts from each other. This cambium does not long retain its mucilaginous form; it is soon metamorphosed into the first liber or bark. The bent vessels of this first liber, in hardening and becoming every day straighter, proceed towards the medullary sheath, round which they compress themselves, and form there the first alburnum, which becomes then the first ligneous zone. The prolongations of the medullary sheath are not all pinched by the formation of this first 